\title{
Virtual Reality in Orthopedic Surgery Training
}

\author{
Laith K Hasan \\ Aryan Haratian \\ Michael Kim (D) \\ loanna K Bolia (D) \\ Alexander E Weber \\ Frank A Petrigliano
}

USC Epstein Family Center for Sports Medicine at Keck Medicine of USC, Los Angeles, CA, USA
Correspondence: Frank A Petrigliano Clinical Orthopaedic Surgery, Chief, USC Epstein Family Center for Sports

Medicine at Keck Medicine of USC, 1520

San Pablo st\#2000, Los Angeles, CA,

90033, USA

Tel + 310 403-044|

Email fpetrigliano@gmail.com

\begin{abstract}
One emerging technology with the potential to improve and further transform the field of orthopaedic surgery is virtual reality (VR). VR has been explored and used in many different specialties with clinical applications, such as psychiatric therapy, pain management, rehabilitation, and traumatic brain injury. Recent studies have suggested that the use of VR during the training of orthopaedic surgery residents produces similar or improved surgical performance by residents. This is an area where VR can provide a tremendous benefit to the field of orthopaedic surgery, as it offers a safe and accessible complement to orthopaedic surgical training outside of the operating room (OR) and without involving patients directly. This review will elucidate the current state of virtual reality use in the training of orthopaedic surgeons and highlight key benefits and challenges in its application as a training resource. Keywords: virtual reality, orthopaedic, surgery, medical education, training
\end{abstract}

\section{Introduction}

Technological advances continue to improve and transform the field of medicine and patient care. One emerging technology is virtual reality (VR). VR is a technology that uses 3-dimensional imaging and databases to create a simulate, interactive environment, typically using a head-mounted display. VR has been explored in many different specialties with clinical applications, such as psychiatric therapy, pain management, rehabilitation, and traumatic brain injury. ${ }^{1-5}$ This technology has the potential for a wide range of uses in orthopaedic surgery, such as surgical training, pre-operative planning, and intra-operative navigation.

Currently, VR is predominantly utilized by orthopaedic surgeons for preoperative planning and training. ${ }^{6}$ There is considerable variability among orthopaedic surgery residency programs in the frequency of use and applications of VR in training residents. ${ }^{7}$ The literature is also limited regarding the exposure to VR training exercises orthopaedic surgery residents receive nationally. Current applications of VR in resident training include arthroscopic simulators, fully immersive operative simulations (eg, trauma management, arthroplasty), bone drilling haptic simulators, and reconstruction simulations. ${ }^{6,8-11}$

Studies exploring VR use have been limited in the past due to infrequent utilization and incomplete development of the technology. However, adoption has accelerated with continued development and more studies have investigated its use during the last decade. Recent studies have suggested that the use of VR during the training of orthopaedic surgery residents improves surgical performance. ${ }^{7,9,10,12}$ This is an area where VR can provide a tremendous benefit to the field of orthopaedic surgery as it offers a safe and accessible complement to orthopaedic surgical training outside of the operating room (OR) without involving patients directly. ${ }^{13}$ Additionally, VR 
simulation may prove especially valuable in the development of arthroscopic skill where the nature of arthroscopic surgery can make it more difficult for residents to develop from assisting and observation alone. ${ }^{14}$ Furthermore, the use of VR has been positively received by residents and associated with increased comfort in perceived operating skills. ${ }^{14,15}$ Recent primary studies referenced in this study are summarized in Table 1.

As discussions around developing a standardized orthopaedic surgical skills curriculum continue, it is important to continue exploring the efficacy of VR in education, challenges in its use, barriers to its adoption, and its safety in surgical training. ${ }^{6,16}$ Overarching advantages and disadvantages of the use of VR simulators in orthopaedic training are summarized in Table 2. This review will elucidate the current state of virtual reality use in the training of orthopaedic surgeons and highlight key benefits and challenges in its application as a training resource.

\section{Virtual Reality Technology Overview}

Virtual reality is a technology capable of producing a simulation that allows users to become immersed in

Table I Summary of Referenced Primary Studies Evaluating the Use of Virtual Reality Simulation in Orthopaedic Surgery Training Published Within Five Years

\begin{tabular}{|c|c|c|c|}
\hline Study & Population & Methods & Outcomes \\
\hline $\begin{array}{l}\text { Logishetty } \\
\text { et al, } 2019^{8}\end{array}$ & $\begin{array}{l}24 \text { surgical trainees naïve to anterior } \\
\text { approach total hip arthroplasty }\end{array}$ & $\begin{array}{l}\text { I:I randomization with } 12 \text { trainees } \\
\text { completing conventional preparation and } \\
\text { I } 2 \text { trainees completing a six-week } \\
\text { immersive VR training using headsets and } \\
\text { a VR-enabled operating room }\end{array}$ & $\begin{array}{l}\text { VR trainees outperformed conventional } \\
\text { trainees requiring less guidance and } \\
\text { instructor intervention, completing more } \\
\text { key steps, more accurately handling } \\
\text { instruments, and finishing in less overall } \\
\text { time in a procedure-based assessment }\end{array}$ \\
\hline $\begin{array}{l}\text { Walbron et al, } \\
2020^{22}\end{array}$ & $\begin{array}{l}107 \text { first-year residents learning } \\
\text { arthroscopy }\end{array}$ & $\begin{array}{l}\text { Non-random assignment to one of three } \\
\text { groups: conventional training only (Group } \\
\text { A, } 76 \text { residents); conventional training with } \\
\text { a single, non-VR supplemental session } \\
\text { (Group B, I7 residents); conventional } \\
\text { training with } 10 \text { hours of VR training } \\
\text { (Group C, } 14 \text { residents) }\end{array}$ & $\begin{array}{l}\text { VR-trained residents (Group C) } \\
\text { outperformed both other groups in } \\
\text { procedure time and measures of accuracy } \\
\text { and instrument handling in two procedure- } \\
\text { based assessments }\end{array}$ \\
\hline $\begin{array}{l}\text { Khanduja et al, } \\
2017^{23}\end{array}$ & $\begin{array}{l}10 \text { residents who had completed } \\
<250 \text { hip arthroscopies each and } 9 \\
\text { faculty who had completed }>250 \text { hip } \\
\text { arthroscopies each }\end{array}$ & $\begin{array}{l}\text { All participants completed a procedure- } \\
\text { based assessment that measured } \\
\text { procedure time, soft tissue and bone } \\
\text { collisions, and instrument handling }\end{array}$ & $\begin{array}{l}\text { Faculty outperformed residents showing } \\
\text { a correlation between experience in hip } \\
\text { arthroscopy and performance in the } \\
\text { simulator supporting the construct validity } \\
\text { of the simulator and its potential to assist in } \\
\text { the development of basic arthroscopic skills }\end{array}$ \\
\hline $\begin{array}{l}\text { Hooper et al, } \\
2019^{34}\end{array}$ & $\begin{array}{l}\text { I4 first-year residents who had } \\
\text { completed one cadaver total hip } \\
\text { arthroplasty }\end{array}$ & $\begin{array}{l}\text { I:I randomization with } 7 \text { trainees } \\
\text { completing conventional preparation and } 7 \\
\text { trainees completing conventional } \\
\text { preparation and two virtual total hip } \\
\text { arthroplasties before completing } \\
\text { their second cadaver total hip arthroplasty }\end{array}$ & $\begin{array}{l}\text { VR-trained residents outperformed the } \\
\text { conventionally trained residents in all steps } \\
\text { of the Ottawa Surgical Competency } \\
\text { Operating Room Evaluation in the second } \\
\text { cadaver total hip arthroplasty }\end{array}$ \\
\hline $\begin{array}{l}\text { Lohre et al, } \\
2020^{36}\end{array}$ & 16 senior residents and 7 faculty & $\begin{array}{l}\text { I:I randomization with } 8 \text { residents and } 3 \\
\text { faculty completing conventional } \\
\text { preparation and } 8 \text { residents and } 4 \text { faculty } \\
\text { completing a single immersive VR training } \\
\text { using headsets and a VR-enabled operating } \\
\text { room }\end{array}$ & $\begin{array}{l}\text { VR-trained participants outperformed the } \\
\text { conventionally trained participants in mean } \\
\text { time and instrument handling while within } \\
\text { groups experience correlated to greater } \\
\text { simulator performance supporting the } \\
\text { construct validity of the simulator and its } \\
\text { potential to assist in the development of } \\
\text { basic arthroscopic skills }\end{array}$ \\
\hline
\end{tabular}


Table 2 Advantages and Disadvantages of Virtual Reality in Teaching Orthopaedic Procedures

\begin{tabular}{|c|c|}
\hline Advantages & Disadvantages \\
\hline $\begin{array}{l}\text { Potential benefit to patient safety } \\
\text { and ethical acceptability }\end{array}$ & $\begin{array}{l}\text { Nascent technology with } \\
\text { imperfect fidelity }\end{array}$ \\
\hline $\begin{array}{l}\text { Opportunity to assess trainee } \\
\text { competence in a consistent and } \\
\text { reproducible manner }\end{array}$ & Expensive to implement \\
\hline $\begin{array}{l}\text { Low-risk environment in which } \\
\text { trainees can practice at any time }\end{array}$ & $\begin{array}{l}\text { Limited evidence regarding } \\
\text { optimal implementation within } \\
\text { residency training }\end{array}$ \\
\hline $\begin{array}{l}\text { Predictable availability regardless } \\
\text { of external factors }\end{array}$ & Limited to certain procedures \\
\hline $\begin{array}{l}\text { Emerging evidence of construct } \\
\text { validity and transferability of } \\
\text { simulator skills }\end{array}$ & $\begin{array}{l}\text { Current simulators only focus on } \\
\text { developing technical skill and do } \\
\text { not incorporate interaction with } \\
\text { the rest of the intraoperative team }\end{array}$ \\
\hline
\end{tabular}

and interact with a three-dimensional, computer-generated multisensory environment. ${ }^{17}$ It typically involves the use of a head-mounted display placing the user inside the experience, thus making the environment and experience feel realistic. VR simulators also characteristically involve the use of handheld devices capable of allowing users to experience force-feedback haptic technology, including visual and physical feedback. These handheld devices are able to be tracked and their movement measured with incredible accuracy, up to the submillimeter. ${ }^{18}$ Beyond the hardware, VR also offers valuable software advantages specific to surgical training, such as automatically measuring and assessing performance through the use of advanced analytics and algorithms. Currently, VR simulators are used in a variety of industries, such as the training of aviation pilots, first responders for disaster preparation, and the military.

\section{Virtual Reality Training in Arthroscopic Surgery}

Arthroscopy has been a particularly challenging skill to train residents on with less opportunity for "hands on" learning. Consequently, many of the studies investigating the use of VR in orthopaedic surgical training have focused on its impact on arthroscopic surgical skills. ${ }^{19}$ Various resources exist to supplement OR experiences for residents, including cadaveric models, sawbone models, low-fidelity simulators, and high-fidelity simulators, including VR. ${ }^{19}$ Arthroscopic simulators, such as the Knee arthroscopy surgical trainer (KAST) developed by the AAOS and the Simbionix Arthromentor, are capable of providing haptic feedback of simulated cartilage and tendon and mimic surgical tools. ${ }^{6}$ Simulators using VR also offer three-dimensional views of anatomy, can simulate realistic events such as bleeding, and also offer recording and analysis on performance. ${ }^{20}$ Consequently, VR simulations offer unique advantages in comparison to more traditional simulators and to other methods of education.

While many simulators exist, the fully immersive VR systems have had the most demonstrated evidence of improvement in surgical skills. ${ }^{21}$ In a study of 107 firstyear residents investigating the effect of VR training on arthroscopy skills, Walbron et al found that after 6 months of VR training, there was significant improvement in surgical performance such as camera alignment, camera path, camera path length, and grasper path length. ${ }^{22}$ However, evidence of translation of these results into real-life skills in the OR is imperative. A study investigating the reliability and validity of the Arthromentor simulator found that there are significant differences in time and operative accuracy between novice and expert groups with two operative tasks, supporting its construct validity. ${ }^{23}$ This finding is promising as it supports the viability of incorporating VR training simulators into residency curriculums. In another multicenter, randomized, blinded study assessing the efficacy of the ArthroSim VR arthroscopic knee simulator, Cannon et al found that residents trained on the VR simulator performed significantly better in the operating room compared to the control group based on the authors' procedural checklist $(\mathrm{p}=0.031)$ and including probing skills $(\mathrm{p}=0.016) .{ }^{24}$ This is noteworthy as it demonstrates transfer validity, meaning that skills acquired through simulations transfer to applicable skills in the OR. Another meta-analysis studying the utility of arthroscopic simulators in transferring skills learned on the model to the OR found that simulator training can improve basic diagnostic arthroscopy skills in a human joint. ${ }^{19}$ Additional studies have also further supported the transfer validity of VR arthroscopic training, including improvement in performance on cadaveric models following VR training. ${ }^{25-28}$ It has also been suggested that training with VR arthroscopic simulators can improve time to completion of diagnostic shoulder arthroscopy. ${ }^{29}$ Therefore, VR may be a viable option to use as a supplemental training tool to improve arthroscopic skills among orthopaedic residents in the OR setting. 
The frequency of use of VR training among residency programs vary. In a survey study conducted in 2015 of orthopaedic residency program directors, sports medicine faculty, and orthopaedic residents, Koehler et al found that only $9.8 \%$ of programs utilized VR as an arthroscopic training resource. ${ }^{30}$ Furthermore, programs vary in the type of simulator available at their institution given the higher cost associated with higher fidelity simulators. ${ }^{31}$ For example, just one high fidelity arthroscopic simulator can cost as high as $\$ 10,000 .{ }^{17}$ It is therefore important to continue to explore the efficacy and value VR training adds to resident education to justify the high cost of the technology. There is also variation in the timing and amount of exposure orthopaedic residents have to VR training. ${ }^{17}$ Most orthopaedic surgery residencies incorporate some form of laboratory-based surgical skills training into the intern year curriculum, with some including VR training. However, the exposure to VR training is often limited to that short period during the first year of training. Studies have revealed how there is increased benefit in the use of VR training tools later in residency when compared to at the start of their training. ${ }^{17}$ Given the potential VR training encompasses in improving more technical surgical skills in residents, it is worth considering integrating further VR exposure later into residents' training.

\section{The Expanding Scope of Virtual Reality Simulation}

The use of VR in surgical education extends beyond arthroscopic simulators. As VR technology continues to advance, so too has its scope - encompassing more areas in orthopaedic surgery such as arthroplasty, fracture management, bone drilling, open procedures, and others. ${ }^{8,11,32}$ With this expansion in scope, VR offers residency programs a valuable tool at enhancing key surgical skills for orthopaedic residents, such as intramedullary nail placement, pedicle screw placement, hemiarthroplasty, and fixation of pelvic fractures. ${ }^{33-35}$ Studies investigating the efficacy of VR in open procedures have also revealed that its utilization is an effective educational tool. ${ }^{10,33-35}$ In a multicenter, blinded, randomized control trial investigating the efficacy and validity of immersive VR training in orthopaedic resident education, Lohre et al found that immersive VR demonstrated improved translational technical and nontechnical skills acquisition over traditional learning in senior orthopaedic residents. ${ }^{36}$ Participants in the study utilized a head-mounted display and haptic controllers in a virtual OR and performed an open glenoid exposure. Another randomized control trial conducted by Logishetty et al observing 24 surgical residents found that VR-trained residents performed a hemiarthroplasty at a higher level than the control cohort as assessed by 2 independent hip surgeons. ${ }^{8}$ The authors found VR-trained surgeons completed $33 \%$ more key steps than controls, were $12^{\circ}$ more accurate in component orientation, and were $18 \%$ faster. $^{8}$ In a stratified, randomized control trial comparing 22 orthopaedic surgery residents' performance on a virtual ulnar surgical fixation simulator to performance on a sawbones simulator, LeBlanc et al found that both simulators distinguished between differing experience levels, demonstrating construct validity. ${ }^{10}$

Given the increasing scope and potential VR offers as a surgical training tool, it may be a particularly useful and effective educational tool. As health-care systems and residency programs continue to deal with the transition to more virtual and remote learning environments, VR can fill the gap left from less frequent in-person activities and patient exposure. ${ }^{37}$ Furthermore, VR offers a solution to patient safety concerns, as it provides trainees access to a variety of techniques that may accurately simulate reallife procedures while minimizing the risk to the patients. ${ }^{38}$ It also allows the possibility for residents to practice and rehearse procedures without a limit on the number of times they can do so, and with less ethical concerns and need for supervision.

\section{Barriers to the Implementation of Virtual Reality in Surgical Training}

The incorporation of VR into surgical training is not without its unique challenges and cost. As previously discussed, there are many different options and types of VR simulators available on the market. It is difficult to draw conclusions on VR simulators across all brands and types, and consequently it is important to understand and be aware of the specific VR simulator being considered. Furthermore, the cost of a simulator is considerably higher than an alternative lower fidelity simulator or educational tool. As an example, the cost of one fracture reduction model using a sawbone kit can cost around $\$ 455$ compared to the cost of the Arthromentor Simbionix's cost of $>$ $\$ 10,000 .^{39,40}$ For many programs, this significant expense may either be unfeasible or not perceived to be valuable enough. Therefore, further research into the efficacy, reliability, and cost-benefit analysis of VR in resident 
education should be done to aid in residency program leadership decision making. More studies validating the translation of VR acquired skills to real world surgical skills need to be conducted.

\section{Satisfaction and Impression of Virtual Reality Among Trainees}

Despite accelerating research and development, studies of virtual reality surgical simulators have yet to rigorously assess trainee satisfaction and impressions. Only two studies included in this literature review focused on this topic. A survey of 142 orthopedic surgeons in 2005 found the majority expected virtual reality simulators to be useful adjuncts to surgical training. ${ }^{13}$ However, only four (3\%) had used a virtual reality simulator at the time of the survey. ${ }^{13}$ In 2018, a survey of 57 osteopathic orthopedic surgery residents demonstrated the increasing adoption of VR simulators with 26 respondents (46\%) having access to a VR simulator. ${ }^{15}$ Impressions continued to be generally positive and are underscored by statements from 53 respondents $(93 \%)$ that they were not comfortable when they performed their first arthroscopic procedure and 36 respondents $(63 \%)$ who indicated it took over 20 arthroscopic procedures before they felt comfortable conducting such a procedure independently. ${ }^{15}$ Of these respondents, $34(60 \%)$ believed skills learned on a simulator would transfer directly into the OR and $33(58 \%)$ stated that all orthopedic residencies should offer access to VR simulators. ${ }^{15}$ The opportunity to practice procedures in a low consequence environment and at any time has been shown to improve performance in the operating room. ${ }^{19}$ Though this effect has not been fully characterized, it is possible that the increase in familiarity and confidence that VR simulators may provide trainees contributes to this effect. This may be particularly important in programs with low patient volume. While VR simulators continue to require further development and implementation, surveyed trainees generally considered VR simulators to be useful additions to their training resources. Further study of trainee impressions and satisfaction is critical to the effective implementation of VR simulators as part of a surgical skills laboratory and a residency program.

\section{Conclusion}

Virtual reality is an emerging technology that has recently increased in use in orthopaedic surgery. While there are many current and potential applications of virtual reality, one particularly beneficial use is in surgical training in orthopaedic surgery. Studies have demonstrated a benefit to using virtual reality as a training tool, including in areas such as arthroscopy, arthroplasty, and trauma. Trainees have responded positively to the growing adoption of virtual reality simulators with the majority stating that all residency programs should offer access to such simulators and that the simulators enable the development of skills immediately transferable to the operating room. However, this technology can be costly and difficult to incorporate into educational curriculums, and consequently further evaluation of the efficacy and value of this technology is needed. In the current state of the technology and given its growing adoption as a training aid, virtual reality simulators are best implemented as supplemental resources secondary to real-world experience in the operating room rather than a panacea. Future studies should explore the effective implementation of VR simulators in orthopaedic training by assessing cost and other factors relevant to adoption and implementation, transferability of skills developed in a simulator to the operating room, and the potential for VR to simulate procedures beyond arthroscopy.

\section{Acknowledgment}

Authors would like to acknowledge The Cappo Family Research Fund.

\section{Disclosure}

None of the authors report any conflict of interest related to this study.

\section{References}

1. Trost Z, Zielke M, Guck A, et al. The promise and challenge of virtual gaming technologies for chronic pain: the case of graded exposure for low back pain. Pain Manag. 2015;5(3):197-206. doi:10.2217/pmt.15.6

2. Andreae MH. Virtual reality in rehabilitation. BMJ. 1996;312(70 22):4-5. doi:10.1136/bmj.312.7022.4

3. Ahern MM, Dean LV, Stoddard CC, et al. The effectiveness of virtual reality in patients with spinal pain: a systematic review and meta-analysis. Pain Pract. 2020;20(6):656-675. doi:10.1111/papr. 12885

4. Murray CD, Patchick E, Pettifer S, Caillette F, Howard T. Immersive virtual reality as a rehabilitative technology for phantom limb experience: a protocol. Cyberpsychol Behav. 2006;9(2):167-170. doi:10. 1089/cpb.2006.9.167

5. Dascal J, Reid M, IsHak WW, et al. Virtual reality and medical inpatients: a systematic review of randomized, controlled trials. Innov Clin Neurosci. 2017;14(1-2):14-21. 
6. Verhey JT, Haglin JM, Verhey EM, Hartigan DE. Virtual, augmented, and mixed reality applications in orthopedic surgery. Int $J$ Med Robot. 2020;16(2):e2067. doi:10.1002/rcs.2067

7. Pedowitz RA, Marsh JL. Motor skills training in orthopaedic surgery: a paradigm shift toward a simulation-based educational curriculum. J Am Acad Orthop Surg. 2012;20(7):407-409. doi:10.5435/jaaos-2007-407

8. Logishetty K, Rudran B, Cobb JP. Virtual reality training improves trainee performance in total hip arthroplasty: a randomized controlled trial. Bone Joint J. 2019;101-b(12):1585-1592. doi:10.1302/0301620x.101b12.Bjj-2019-0643.R1

9. Cannon WD, Nicandri GT, Reinig K, Mevis H, Wittstein J. Evaluation of skill level between trainees and community orthopaedic surgeons using a virtual reality arthroscopic knee simulator. $J$ Bone Joint Surg Am. 2014;96(7):e57. doi:10.2106/jbjs.M.00779

10. LeBlanc J, Hutchison C, Hu Y, Donnon T. A comparison of orthopaedic resident performance on surgical fixation of an ulnar fracture using virtual reality and synthetic models. J Bone Joint Surg Am. 2013;95(9):e60, S1-5. doi:10.2106/jbjs.K.01284

11. Tsai MD, Hsieh MS, Tsai CH. Bone drilling haptic interaction for orthopedic surgical simulator. Comput Biol Med. 2007;37 (12):1709-1718. doi:10.1016/j.compbiomed.2007.04.006

12. Seymour NE, Gallagher AG, Roman SA, et al. Virtual reality training improves operating room performance: results of a randomized, double-blinded study. Ann Surg. 2002;236(4):458-63; discussion 463-4. doi:10.1097/00000658-200210000-00008

13. Blyth P, Anderson IA, Stott NS. Virtual reality simulators in orthopedic surgery: what do the surgeons think? J Surg Res. 2006;131 (1):133-9; discussion 140-2. doi:10.1016/j.jss.2005.08.027

14. Aïm F, Lonjon G, Hannouche D, Nizard R. Effectiveness of virtual reality training in orthopaedic surgery. Arthroscopy. 2016;32 (1):224-232. doi:10.1016/j.arthro.2015.07.023

15. Keith K, Hansen DM, Johannessen MA. Perceived value of a skills laboratory with virtual reality simulator training in arthroscopy: a survey of orthopedic surgery residents. J Am Osteopath Assoc. 2018;118(10):667-672. doi:10.7556/jaoa.2018.146

16. Karam MD, Pedowitz RA, Natividad H, Murray J, Marsh JL. Current and future use of surgical skills training laboratories in orthopaedic resident education: a national survey. J Bone Joint Surg Am. 2013;95 (1):e4. doi:10.2106/jbjs.L.00177

17. Atesok K, MacDonald P, Leiter J, et al. Orthopaedic education in the era of surgical simulation: still at the crawling stage. World J Orthop. 2017;8(4):290-294. doi:10.5312/wjo.v8.i4.290

18. Székely G, Satava RM. Virtual reality in medicine. Interview by Judy Jones. BMJ. 1999;319(7220):1305. doi:10.1136/bmj.319.7220.1305

19. Frank RM, Wang KC, Davey A, et al. Utility of modern arthroscopic simulator training models: a meta-analysis and updated systematic review. Arthroscopy. 2018;34(5):1650-1677. doi:10.1016/j.arthro.20 17.10 .048

20. Nagendran M, Gurusamy KS, Aggarwal R, Loizidou M, Davidson BR. Virtual reality training for surgical trainees in laparoscopic surgery. Cochrane Database Syst Rev. 2013;2013(8): Cd006575. doi:10.1002/14651858.CD006575.pub3

21. Lohre R, Warner JJP, Athwal GS, Goel DP. The evolution of virtual reality in shoulder and elbow surgery. JSES Int. 2020;4(2):215-223. doi:10.1016/j.jseint.2020.02.005

22. Walbron P, Common H, Thomazeau H, et al. Virtual reality simulator improves the acquisition of basic arthroscopy skills in first-year orthopedic surgery residents. Orthop Traumatol Surg Res. 2020;106 (4):717-724. doi:10.1016/j.otsr.2020.03.009

23. Khanduja V, Lawrence JE, Audenaert E. Testing the construct validity of a virtual reality hip arthroscopy simulator. Arthroscopy. 2017;33(3):566-571. doi:10.1016/j.arthro.2016.09.028
24. Cannon WD, Garrett WE Jr, Hunter RE, et al. Improving residency training in arthroscopic knee surgery with use of a virtual-reality simulator. A randomized blinded study. J Bone Joint Surg Am. 2014;96(21):1798-1806. doi:10.2106/jbjs.N.00058

25. Butler A, Olson T, Koehler R, Nicandri G. Do the skills acquired by novice surgeons using anatomic dry models transfer effectively to the task of diagnostic knee arthroscopy performed on cadaveric specimens? J Bone Joint Surg Am. 2013;95(3):e15 (1-8). doi:10. 2106/jbjs.L.00491

26. Rebolledo BJ, Hammann-Scala J, Leali A, Ranawat AS. Arthroscopy skills development with a surgical simulator: a comparative study in orthopaedic surgery residents. Am J Sports Med. 2015;43 (6):1526-1529. doi:10.1177/0363546515574064

27. Rose K, Pedowitz R. Fundamental arthroscopic skill differentiation with virtual reality simulation. Arthroscopy. 2015;31(2):299-305. doi:10.1016/j.arthro.2014.08.016

28. Bartlett JD, Lawrence JE, Stewart ME, Nakano N, Khanduja V. Does virtual reality simulation have a role in training trauma and orthopaedic surgeons? Bone Joint J. 2018;100-b(5):559-565. doi:10.1302/ 0301-620x.100b5.Bjj-2017-1439

29. Henn RF 3rd, Shah N, Warner JJ, Gomoll AH. Shoulder arthroscopy simulator training improves shoulder arthroscopy performance in a cadaveric model. Arthroscopy. 2013;29(6):982-985. doi:10.1016/j. arthro.2013.02.013

30. Koehler R, John T, Lawler J, Moorman C 3rd, Nicandri G. Arthroscopic training resources in orthopedic resident education. J Knee Surg. 2015;28(1):67-74. doi:10.1055/s-0034-1368142

31. Agyeman KD, Summers SH, Massel DH, Mouhanna J, Aiyer A, Dodds SD. Innovation in orthopaedic surgery education: novel tools for modern times. J Am Acad Orthop Surg. 2020;28(18):e782-e792. doi:10.5435/jaaos-d-19-00411

32. Marchand LS, Sciadini MF. Simulation training in fracture surgery. J Am Acad Orthop Surg. 2020;28(21):e939-e947. doi:10.5435/jaaosd-20-00076

33. Gasco J, Patel A, Ortega-Barnett J, et al. Virtual reality spine surgery simulation: an empirical study of its usefulness. Neurol Res. 2014;36 (11):968-973. doi:10.1179/1743132814y.0000000388

34. Hooper J, Tsiridis E, Feng JE, et al. Virtual reality simulation facilitates resident training in total hip arthroplasty: a randomized controlled trial. J Arthroplasty. 2019;34(10):2278-2283. doi:10.1016/j. arth.2019.04.002

35. Sugand K, Akhtar K, Khatri C, Cobb J, Gupte C. Training effect of a virtual reality haptics-enabled dynamic hip screw simulator. Acta Orthop. 2015;86(6):695-701. doi:10.3109/17453674.2015.1071111

36. Lohre R, Bois AJ, Athwal GS, Goel DP. Improved complex skill acquisition by immersive virtual reality training: a randomized controlled trial. J Bone Joint Surg Am. 2020;102(6):e26. doi:10.2106/ jbjs.19.00982

37. Kogan M, Klein SE, Hannon CP, Nolte MT. Orthopaedic education during the COVID-19 pandemic. J Am Acad Orthop Surg. 2020;28 (11):e456-e464. doi:10.5435/jaaos-d-20-00292

38. McCloy R, Stone R. Science, medicine, and the future. Virtual reality in surgery. BMJ. 2001;323(7318):912-915. doi:10.1136/bmj.323.73 18.912

39. Goff BA, Lentz GM, Lee D, Houmard B, Mandel LS. Development of an objective structured assessment of technical skills for obstetric and gynecology residents. Obstet Gynecol. 2000;96(1):146-150. doi:10.1016/s0029-7844(00)00829-2

40. Egan C, Egan R, Curran P, Bryan K, Fleming P. Development of a model for teaching manipulation of a distal radial fracture. $J$ Bone Joint Surg Am. 2013;95(5):433-438. doi:10.2106/jbjs.J.01791 


\section{Publish your work in this journal}

Advances in Medical Education and Practice is an international, peerreviewed, open access journal that aims to present and publish research on Medical Education covering medical, dental, nursing and allied health care professional education. The journal covers undergraduate education, postgraduate training and continuing medical education including emerging trends and innovative models linking education, research, and health care services. The manuscript management system is completely online and includes a very quick and fair peer-review system. Visit http://www.dovepress.com/testimonials.php to read real quotes from published authors. 